Research Article

\title{
Bioinsecticide Production from Cigarette Wastes
}

\author{
Badhane Gudeta, ${ }^{1}$ Solomon $\mathrm{K}^{2}$ and $\mathrm{M}$. Venkata Ratnam ${ }^{1}{ }^{1}$ \\ ${ }^{1}$ Department of Chemical Engineering, Mettu University, Metu, Ethiopia \\ ${ }^{2}$ School of Chemical and Bio Engineering, Addis Ababa Institute of Technology, Addis Ababa, Ethiopia
}

Correspondence should be addressed to M. Venkata Ratnam; mvratnam81@gmail.com

Received 25 August 2021; Revised 15 October 2021; Accepted 25 October 2021; Published 8 November 2021

Academic Editor: Dimitar Peshev

Copyright (c) 2021 Badhane Gudeta et al. This is an open access article distributed under the Creative Commons Attribution License, which permits unrestricted use, distribution, and reproduction in any medium, provided the original work is properly cited.

\begin{abstract}
Tobacco, one of the most significant nonfood crops, is critical to agriculture worldwide. The tobacco processing business creates a significant amount of hazardous tobacco waste containing nicotine, and only a tiny portion of it gets recycled. Nicotine, the primary component of tobacco products such as cigarettes, is an alkaloid and can be used as an insecticide. This research aims to extract nicotine from discarded cigarette butts and utilize it as an insecticide. Extraction, emulsification, and efficiency testing on cabbage aphids are all part of the procedure. The initial extraction tests used a solvent combination of ethanol and methanol in various ratios, with a $3: 1$ ratio yielding the best results. Temperature $\left(30-60^{\circ} \mathrm{C}\right)$, extraction length (4-6 hrs), and sodium hydroxide concentration $(1-3 \mathrm{M})$ are the independent variables studied for extraction parameters, and the optimal conditions are determined using Design-Expert, response surface approach central composite design (RSM-CCD). In addition, artificial neural network (ANN) studies with MATLAB were used to accurately forecast extraction yield. The extracted product was evaluated using a gas chromatography-mass spectrometry (GC-MS) and a UV/visible spectrophotometer. The ideal crude extract yield and nicotine content were 17.75 and $3.26 \%$, respectively, at the optimal conditions of temperature $60^{\circ} \mathrm{C}$, time $4 \mathrm{hrs}$, and $\mathrm{NaOH}$ concentration $2.83 \mathrm{M}$ with desirability of 0.832 . The nicotine extracted was emulsified by combining the crude extract with a combination of palm oil and surfactants. Density, viscosity, $\mathrm{pH}$, flash point, and surface tension of the emulsified concentration were measured and reported as $1.01 \pm 0.01 \mathrm{~g} / \mathrm{ml}, 585.33 \pm 2.52 \mathrm{mPa} \mathrm{s}, 9.37 \pm 0.03,87.96 \mathrm{C}$, and $34.10 \mathrm{mN} / \mathrm{m}$, respectively. On the cabbage aphid, the emulsified concentrated extract performed best at a ratio of $1: 100$ (emulsified concentrated to solvent).
\end{abstract}

\section{Introduction}

Tobacco (Nicotiana tabacum L.) is one of the largest grown crops on the planet. It is an important crop commercially, agriculturally, and socially. Tobacco has been used for chewing, sniffing, and smoking. Cigarette butts are becoming a greater global environmental burden, with annual discards rising from 4.5 trillion in 2006 to 5.7 trillion in 2016, with the potential for further increase, a prediction of nine trillion by 2025 [1]. The chemical composition of cigarette butts, which contains approximately 4000 different chemicals [2], as well as their persistence in the environment and potential negative effects, is a major environmental threat. Since the bulk of these chemicals are toxic, they regularly seep into aquatic habitats, putting water supplies and aquatic species at risk [3]. Cigarette butts are dangerous as they contain toxic chemicals, including arsenic, nicotine, polycyclic aromatic hydrocarbons, and heavy metals [1, 4]. Around $30 \%$ of a normal cigarette butt comprises filters, tobacco fiber, and ash.

Africa has a low cigarette smoking rate compared to the western world, but it has been rapidly growing recently. The population of Ethiopia is growing, and so is the number of individuals who smoke cigarettes. In terms of smoking rates, Ethiopia was rated $21^{\text {st }}$ in Africa and $130^{\text {th }}$ globally in 2019 . The number of smokers continues to grow year after year. Research on the prevalence, distribution, and socioeconomic factors of cigarette smoking, as well as the amount of nicotine in Ethiopian cigarettes, has been conducted by several researchers [5-8]. Cigarette waste may be utilized or recycled to make a variety of items. At China's plastic pyrolysis plants, thousands of cigarettes are recycled into industrial 
plastic goods such as shipping pallets, railway sleepers, bricks, and ashtrays. People may also recycle their old cigarette butts for free, with over 7000 cigarette recycling bins presently available in nine countries, including the United States, the United Kingdom, and Australia [1, 3, 9]. According to Vahidhabanu [10], crude extracts from discarded cigarette butts might be utilized as a corrosion inhibitor for J55 oil tubular steel. Cigarette butts are utilized as a fiber modifier in bitumen and asphalt concrete. Research shows the successful usage of cigarette butts in lightweight bricks $[11,12]$.

Nicotine is an alkaloid that is found in tobacco [13]. Since 1690, the insecticidal effects of nicotine have been investigated. Because of its short environmental persistence and target pest selectivity, nicotine is commonly considered a potential alternative to traditional insecticides for crop protection and public health. To control insect pests, farmers employ chemical pesticides and fungicides, which result in residual chemicals being passed on to customers. According to a $2008 \mathrm{WHO}$ report, poor countries utilized $25 \%$ of the world's chemical pesticide production $[4,14,15]$. Nontarget species such as natural insect adversaries, pollinators, and domestic and wild animals are all affected by chemical pesticides [16]. As a consequence of the negative impacts of chemical pesticides on nontarget species, there is a need for alternatives. The economy and the environment will benefit through bioinsecticide/pesticide production from spent cigarette materials [17]. Bio pesticide/insecticide preparation using nicotine from cigarette butts is a relatively new study to explore. There is virtually little available literature. To manage armyworm infestations, cigarette butts are utilized as a nicotine source in the manufacture of a bioinsecticide [15]. Nicotine was collected from cigarette butts using several techniques in preparation for its possible use as a natural pesticide [18]. Cabbage cultivation in Ethiopia is significantly low compared to other fruits and cereal crops due to insect infestations. As a consequence, cabbage aphids were chosen as a model crop for evaluating the insecticide produced from cigarette butts.

The purpose of this research is to characterize and improve nicotine recovery from cigarette waste. Using the design of experiments, response surface approach, and central composite design (RSM-CCD), the influence of temperature, time, and $\mathrm{NaOH}$ concentration on the extraction process was investigated. Artificial neural network (ANN) computations using MATLAB were employed for yield prediction. The extracted insecticide was emulsified to improve penetration through the insects' skin. An emulsified concentrated insecticide's density, viscosity, $\mathrm{pH}$, surface tension, flashpoints, and stability were studied. Cabbage aphids were employed to assess the effectiveness of the emulsion.

\section{Materials and Methods}

2.1. Materials. The chemicals used for this study were procured from different sources. Pure standard nicotine was borrowed from NTE Company. Pure $96 \%$ ethanol and $\mathrm{NaOH}$ were purchased from MTET Laboratory Chemical
Trading PLC. 99.5\% pure methanol was purchased from Heparin Laboratory Chemical Trading PLC. Emulsifiers (sodium lauryl sulfate and ethoxylated sorbitan ester) were taken from ABIM Soap and Detergent Factory. The experiment was conducted at Addis Ababa Institute of Technology (AAiT), School of Chemical and Bio Engineering, Biochemical Engineering Laboratory. Physicochemical characterizations, such as viscosity, density, $\mathrm{pH}$, stability study, and UV/vis analysis, were performed in the AAiT laboratory, and GC-MS analysis, bomb calorimeter, and du Nouy ring equipment available at Addis Ababa Science and Technology University were used for the study.

\subsection{Raw Material Collection and Characterization.} Cigarettes of seven brands (Nyala Premium, Nyala, Delight, Winston, Marlboro, Oris, and BR) were purchased from shops, while trash cigarettes were collected from households in the surrounding area of Addis Ababa. The amount of tobacco remaining in the cigarette butt varies depending on the length. The diameters of the entire cigarette; filter paper; full tobacco-containing section; and $1 / 4,1 / 3,1 / 2$, $2 / 3$, and $3 / 4$ of tobacco-containing parts were measured, as well as their weights with and without cigarette paper to estimate the leftover tobacco (as shown in Figure 1).

The moisture content was determined using the loss on drying (LOD) moisture technique. The weight of tobacco filler extracted from butts and raw cigarettes was measured using this approach before and after $3.30 \mathrm{hrs}$ of drying at $65^{\circ} \mathrm{C}$, and the $\%$ of moisture removed from the tobacco filler was calculated as follows:

$$
\text { Moisture content }(\%)=\frac{W, \text { initial }-W, \text { dried }}{W, \text { initial }} * 100 \text {, }
$$

where $W$, initial = weight of the sample before drying and $W$, dried $=$ weight of the sample after drying.

2.3. Nicotine Extraction from Tobacco. After crushing the material to pass through $3.15 \mathrm{~mm}$ mesh, $6 \mathrm{~g}$ was put into a series of $250 \mathrm{~mL}$ round bottle flasks. The flasks were then filled with a mixture of methanol and ethanol in various proportions $(60: 0,45: 15,30: 30,15: 45,0: 60)$ and $80 \mathrm{ml}$ of $5 \mathrm{M} \mathrm{NaOH}$. The extraction was done in a water bath at $65^{\circ} \mathrm{C}$ for $3.30 \mathrm{hrs}$ (grant, precision, and immersion thermostat bath and circulation TX 150 and TXF 200). The extract and filter cake were separated using filter paper and vacuum filtering once the extraction was done. The filtration process was done twice more, with the filter cake being washed with $10 \mathrm{~mL}$ ethanol each time to remove any residual nicotine. To get viscous crude extracts, the solvent was evaporated from the filtrate using a vacuum evaporator at $100^{\circ} \mathrm{C}$ and $45 \mathrm{rpm}$ for $2 \mathrm{hrs}$ from the filtrate to get the viscous crude extract. Figure 2 represents a schematic diagram of the whole process.

The nicotine content in the extract was determined by using a UV/Visible 3200 spectrophotometer. The yield and content of nicotine have a direct proportion unless there was 


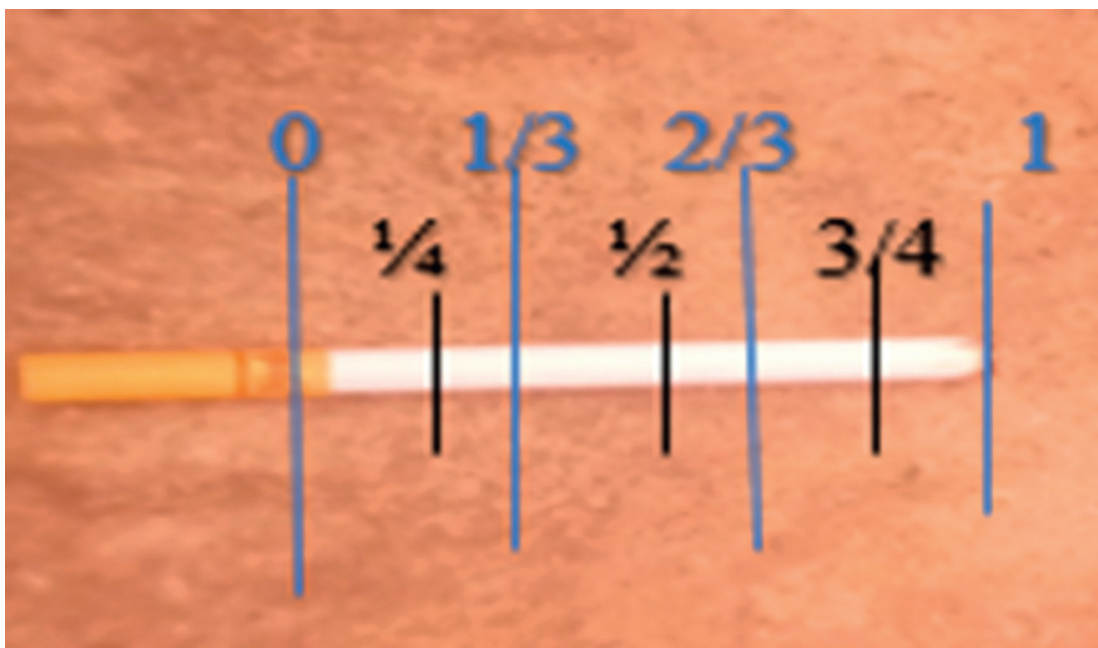

FIgure 1: Possible lengths of cigarette butts containing remnant tobacco.

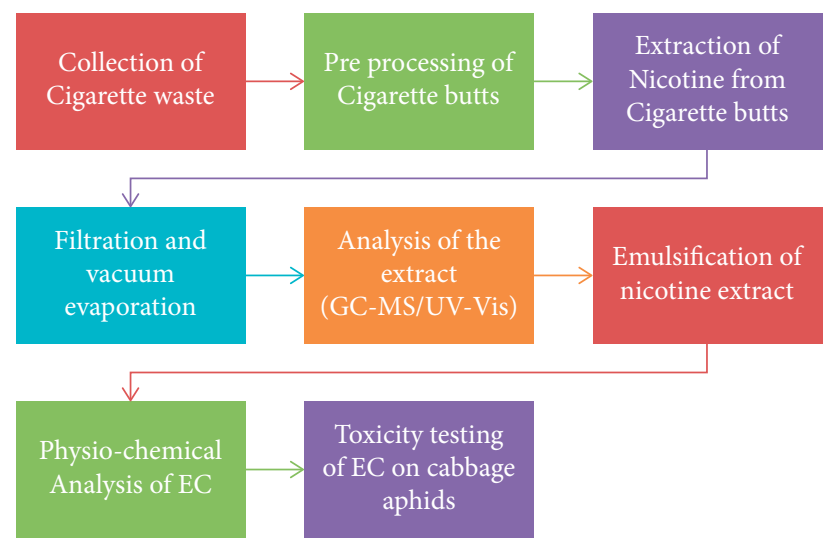

Figure 2: The schematic representation of the process.

an effect of parameters on one of the responses over the other during the process.

The yield was calculated by

$$
\text { yield, } \%=\frac{m 1-m 2}{m 1} \times 100 \text {, }
$$

where $m_{1}$ is the mass of dried tobacco filler before extraction. $m_{2}$ is the mass of filter cake (dried and measured until the mass became constant).

The $\%$ of nicotine content was determined by

$$
\text { nicotine content }=\frac{\text { concentration of nicotine }(g / l) \times \text { volume of the extracts }(l)}{\text { mass of the tobacco leaves }(g)} \times 100 \text {. }
$$

2.3.1. GC-MS Studies. GC-MS 6800 was used to examine the extract. A flame ionization detector was used to analyze the GC-MS 6800 (rectangular with length of $105 \mathrm{~cm}$, width of $60 \mathrm{~cm}$, and height of $50 \mathrm{~cm}$ ) (FID). With a $2 \mathrm{ml} / \mathrm{min}$ flow rate, helium $99.999 \%$ was employed as a carrier gas (mobile phase). The stationary phase was made by combining methanol and ionized water in $80: 20 \mathrm{v} / \mathrm{v}$ methanol: distilled water ratio. Using the split mode, a microliter sample injection volume was set from 70 to $200^{\circ} \mathrm{C}(1 \mathrm{~min}$ hold $)$ and then raised to $300^{\circ} \mathrm{C}$ at a rate of $10^{\circ} \mathrm{C} / \mathrm{min}$. The oven temperature is set at $200-300^{\circ} \mathrm{C}$ at a rate of $10^{\circ} \mathrm{C}$ per minute. In this study, ion monitoring (SIM) mode was utilized. The operation of the MSD was in the electron impact (EI) mode at $70 \mathrm{eV}, 230^{\circ} \mathrm{C}$. The major ions peak in the scan mode (10-200 a.m.u). The total retention was $25 \mathrm{~min}$.

2.3.2. Design of Experiments: RSM-CCD. Response surface methodology (RSM) integrates statistical and arithmetic techniques for the design, parameter analysis, and process optimization of experiments. Since it offers a full understanding of component-based interaction effects with fewer 
experimental runs, central composite design (CCD) is RSM's main approach for designing environmentally friendly processes $[19,20]$. The total number of test runs required is $2^{k}+2 k+C_{\mathrm{o}}$, whereby $k$ is the number of factors, $2 \mathrm{k}$ is the number of cubic runs, $2 \mathrm{k}$ is the number of runs, and $\mathrm{C}_{0}$ is the number of runs of the center point. Design-Expert version 12 was used to in the present study to conduct the tests, which included the surface response techniques and a central composite design (CCD). Temperature $\left(A: 30-60^{\circ} \mathrm{C}\right)$, extraction time (B: 4-6hrs), and $\mathrm{NaOH}$ concentration (C: 1-3 M) were used to construct the experiment. The factors and their levels employed for the present study are presented in Table 1. The fit model and optimal conditions for independent variables were estimated using the ANOVA technique.

2.3.3. ANN Modeling. In recent years, the artificial neural network (ANN) has gained appeal as a sophisticated optimization and simulation tool because of its powerful prediction and estimation skills $[21,22]$. ANN beats RSM in terms of prediction skills, according to numerous published studies. To predict a nonlinear relationship between input parameters and response variables, an artificial neural network was used $[19,23,24]$. The ANN model was built using the same experimental dataset as the RSM model: 70\% (14 points) for network training, 15\% (3 points) for validation, and 15\% (3 points) for network testing. The ANN design's hidden layer reflected the output signal created by an activation function that was generally nonlinear and supplied each neuron with a weighted quantity of input variables. The number of layers and neurons at various levels of the ANN architecture has been adjusted to achieve accuracy. The ANN contains a three-neuron input layer representing three independent variables: $\mathrm{A}, \mathrm{B}$, and $\mathrm{C}$, as well as a hidden layer with an output layer representing the responses. Using the MATLAB Neural Network Toolbox ${ }^{\text {TM }}$, a multilayer architecture for ANN feeding was created. The lowest MSE and highest $R^{2}$ were chosen as measures of the optimal training performance of this development ANN model.

2.4. Emulsion. At room temperature, the emulsification process was used to create a stable emulsion formulation. Nicotine and other volatile constituents in tobacco extract could easily evaporate. Hence, to avoid evaporation, oils, such as rice bran oil, palm oil, and soy bean oil, will be used. Since the two phases, oil and water, are not miscible, emulsifiers will be used to blend them properly to a stable suspension. In the present study, $1: 4$ (wt/wt) ratios of palm oil and emulsifiers sodium lauryl sulfate (anionic surfactant) and ethoxylated sorbitan ester (nonionic surfactant) were used. $13.62 \mathrm{~g}$ of the mixture was added to $54.46 \mathrm{~g}$ of crude extract (10 g nicotine) according to the protocol [25]. Finally, the mixture was homogenized using a homogenizer. Specific gravity, viscosity, surface tension, flash point, $\mathrm{pH}$, and emulsion stability are the most essential physicochemical characteristics examined to determine the efficacy of emulsification. Stability studies were conducted under
TABLE 1: Factors and their levels used for the study.

\begin{tabular}{lcc}
\hline Factors & \multicolumn{2}{c}{ Level } \\
& Low & High \\
\hline A : temperature $\left({ }^{\circ} \mathrm{C}\right)$ & 30 & 60 \\
B : time of extraction $(\mathrm{hr})$ & 4 & 6 \\
$\mathrm{C}: \mathrm{NaOH}$ concentration $(\mathrm{M})$ & 1 & 3 \\
\hline
\end{tabular}

different temperatures under an incubator for a time period between 1 and $18 \mathrm{hrs}$. In each cycle, the samples were kept at $4^{\circ} \mathrm{C}$ for $18 \mathrm{hrs}$ and at $45^{\circ} \mathrm{C}$ for $18 \mathrm{hrs}$. The sample was then evaluated for its stability after physical properties; for example, changes of physical appearance, $\mathrm{pH}$, and density were reevaluated [26].

2.5. Efficiency Testing for EC. The concentrated emulsion (EC) was diluted in the ratios of $0.5: 100,1: 100,1.5: 100,2$ : $100,3: 100$, and $4: 100(\mathrm{w} / \mathrm{w})$. The aphids used in the study were sprayed with the dilution that was created. The time at which the aphids died at a certain dilution ratio and time could be seen with the naked eye and confirmed with a microscope. The efficiency (i) is estimated as

$$
\text { efficiency }(i), \%=\frac{\text { number of died aphids }}{\text { total aphids present }} \times 100 \text {. }
$$

\section{Results and Discussion}

3.1. Raw Material Characterization. Filter paper dimensions, internal diameters, and length differ between cigarette brands. Knowing the size of a cigarette helps you to estimate the amount of tobacco and cigarette butt in the cigarette. The dimensions for all the seven brands collected are presented in Table 2. The average length of all cigarette brands was $87.286 \pm 6.396 \mathrm{~mm}$, with a weight of $0.843 \pm 0.159 \mathrm{~g}$. The approximate range of cigarette butts mostly thrown to the environment was between 28.473 and $61.413 \mathrm{~mm}$. In this range, a single cigarette butt produced 0.225 to $0.571 \mathrm{~g}$ of cigarette butts and 0.0166 to $0.3864 \mathrm{~g}$ of residual tobacco. Regression models might be used to calculate the weight of a single cigarette butt and the amount of tobacco left in a smoked cigarette based on the size of cigarette butts.

The moisture content determination of tobacco filler is one of the most important factors in improving both the quality and quantity of yields. The moisture content of all brands of cigarettes is not the same. Hence, the weight of the cigarette sample for all the brands before drying is measured, and the average value computed is obtained as $4.941 \mathrm{~g}$ (W, initial). Similarly, the weight of the same samples after drying is calculated, and the average value computed is obtained as $4.498 \mathrm{~g}$ (W, dry). The average moisture content calculated using equation (1) was obtained as $8.996 \%$. The moisture content in the cigarette filler is low compared to green leaf threshing tobacco because it dried under the drying chamber during cigarette processing. The moisture content of green leaf threshing of tobacco is from 17 to $22 \%$. 
TABLE 2: Weight of remnant tobacco remained in different possible sizes of cigarette/butts.

\begin{tabular}{lcc}
\hline Average length of cigarette/butts of 7 brands $(\mathrm{mm})$ & Weight of paper + tobacco $(\mathrm{g})$ & Weight of tobacco $(\mathrm{g})$ \\
\hline 87.29 & 0.843 & 0.659 \\
71.04 & 0.672 & 0.494 \\
65.59 & 0.615 & 0.437 \\
54.71 & 0.501 & 0.329 \\
43.84 & 0.386 & 0.221 \\
38.43 & 0.329 & 0.165 \\
22.14 & 0.158 & 0 \\
\hline
\end{tabular}

TABle 3: Nicotine concentration extracted at different ethanol-to-methanol ratios.

\begin{tabular}{lcc}
\hline Sample code & Ethanol: methanol $(\mathrm{ml} / \mathrm{ml})$ & Concentration of nicotine in a sample $(\mu \mathrm{g} / \mathrm{ml})$ \\
\hline A & $0: 60$ & 318.65 \\
B & $15: 45$ & 381.73 \\
C & $30: 30$ & 367.29 \\
D & $45: 15$ & 396.35 \\
E & $60: 0$ & 321.56 \\
\hline
\end{tabular}

3.2. Nicotine Extraction from Tobacco. To determine the critical ratio of methanol to ethanol for best nicotine extraction, experiments were carried out at different methanol to ethanol ratios. The results are presented in Table 3. The highest nicotine concentration was obtained using $75 \%$ ethanol and $25 \%$ methanol extraction, which was chosen for future operations.

\subsubsection{GC-MS Studies}

(1) Qualitative Determination of Nicotine Extracts. Taking the structure of the nicotine molecule, the cleavage of some fragments at one or more bonds gave different mass-tocharge ratios. The molecular ion of $\mathrm{m} / z 162$ indicates the identity of nicotine, and the intensity that occurred at $\mathrm{m} / z$ of 133 shows the abundance of nicotine molecules in the sample. When the bond between the two nitrogen heterocyclic was broken, two fragments were formed and their peaks displayed on the graph. The base peak (BP) appears at $\mathrm{m} / z=84(99.99 \%)$ and the peak at $\mathrm{m} / z=78$ (2.99). The intensity at $\mathrm{m} / z=84$ would be a qualitative determinant of nicotine [27]. Figure 3 represents the qualitative analysis of the sample, which confirms the nicotine presence.

(2) Quantitative Determination of Nicotine. Standard nicotine was used to determine the quantitative value of nicotine. Standard nicotine concentrations were obtained by dissolving nicotine in methanol (HPLC grade, 99.5\%), and the peak area for each concentration was measured at the prescribed retention period. The graph was then calibrated by plotting the peak area versus standard nicotine concentration. The concentration of nicotine in the sample was determined using this calibration.

3.2.2. Design of Experiments: RSM-CCD. Using the RSMCCD design at alpha $(\alpha=2)$, the effects of different parameters and their ideal circumstances for extracting active compounds from tobacco fillers of cigarette butts were

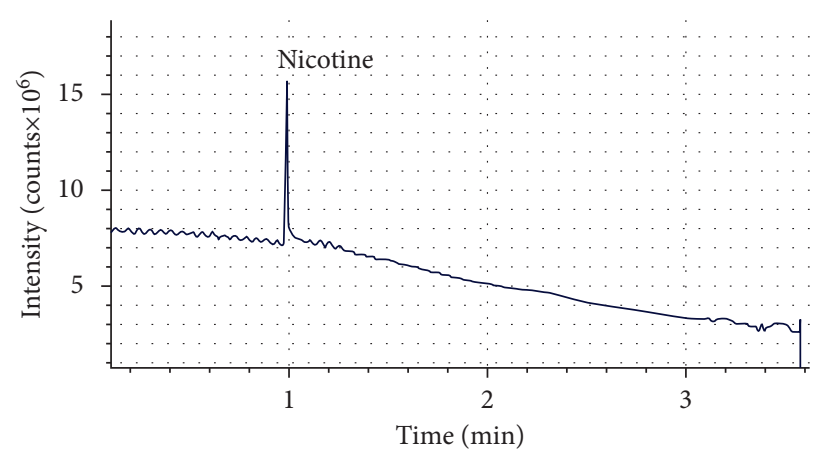

FIGURE 3: GC-MS scanned sample for qualitative analysis.

found. After the standard curve was constructed for calibration, the concentration of nicotine in the extract for each component was measured using an ultraviolet visible (UV/ Vis 3200) spectrophotometer 3200. The design matrix of the variables and outcomes, yield of crude extracts (response 1), and nicotine content (response 2) are shown in Table 4.

To assess the model's suitability, a variety of criteria should be satisfied, including $p$ value, lack of fit F-value, regression ratio, and others. The statistical significance of the model and the components would be established at $(\alpha=5 \%)$ if the probability $(p)$ value was less than $5 \%$. The F-value for lack of fit is a measure of the influence of all variables on the answer. The greater the value of lack of fit, the better, since it indicates that the model has the best chance of fitting.

The model is significant in both situations, with F-values of 1614.91 for response 1 and 1025.19 for response 2 (Tables 5 and 6). $p$ values of less than 0.0500 indicate that model terms are significant. In this scenario, essential model terms include $\mathrm{A}, \mathrm{B}$, $\mathrm{C}, \mathrm{AB}, \mathrm{AC}, \mathrm{BC}, \mathrm{A}^{2}, \mathrm{~B}^{2}, \mathrm{C}^{2}$. If the value is more than 0.1000 , the model terms are irrelevant. Compared to pure error, the F-values for lack of fit for responses 1 and 2 are 0.11 and 0.82 , respectively, showing that lack of fit is not significant. There is a 98.64\% and $58.32 \%$ chance, respectively, that a high lack of fit F-value will occur due to noise for responses 1 and 2. It is okay if there is a little discrepancy; the model is chosen carefully. 
TABLE 4: Designed variables were analyzed by central composite design.

\begin{tabular}{|c|c|c|c|c|c|c|}
\hline Std. & Run & $\begin{array}{c}\text { Factor } 1 \\
\text { A : temperature } \\
{ }^{\circ} \mathrm{C}\end{array}$ & $\begin{array}{c}\text { Factor } 2 \\
\text { B : time of extraction } \\
\text { Hr }\end{array}$ & $\begin{array}{c}\text { Factor } 3 \\
\mathrm{C}: \mathrm{NaOH} \text { concentration } \\
\mathrm{M}\end{array}$ & $\begin{array}{c}\text { Response } 1 \\
\text { Yield of crude extracts } \\
\%\end{array}$ & $\begin{array}{c}\text { Response } 2 \\
\text { Nicotine content } \\
\%\end{array}$ \\
\hline 1 & 17 & 30 & 4 & 1 & 14.204 & 2.6508 \\
\hline 2 & 3 & 60 & 4 & 1 & 16.689 & 3.1318 \\
\hline 3 & 12 & 30 & 6 & 1 & 16.194 & 3.1408 \\
\hline 4 & 16 & 60 & 6 & 1 & 17.489 & 3.2131 \\
\hline 5 & 8 & 30 & 4 & 3 & 15.426 & 2.8368 \\
\hline 6 & 4 & 60 & 4 & 3 & 17.778 & 3.2496 \\
\hline 7 & 9 & 30 & 6 & 3 & 15.471 & 3.2016 \\
\hline 8 & 20 & 60 & 6 & 3 & 16.628 & 3.1768 \\
\hline 9 & 2 & 15 & 5 & 2 & 14.345 & 3.016 \\
\hline 10 & 7 & 75 & 5 & 2 & 17.958 & 3.4786 \\
\hline 11 & 14 & 45 & 3 & 2 & 16.218 & 2.8793 \\
\hline 12 & 19 & 45 & 7 & 2 & 17.014 & 3.2867 \\
\hline 13 & 18 & 45 & 5 & 0 & 15.457 & 2.7962 \\
\hline 14 & 10 & 45 & 5 & 4 & 15.836 & 2.9696 \\
\hline 15 & 11 & 45 & 5 & 2 & 16.457 & 3.0968 \\
\hline 16 & 6 & 45 & 5 & 2 & 16.556 & 3.1087 \\
\hline 17 & 13 & 45 & 5 & 2 & 16.498 & 3.1081 \\
\hline 18 & 15 & 45 & 5 & 2 & 16.448 & 3.0882 \\
\hline 19 & 5 & 45 & 5 & 2 & 16.45 & 3.0893 \\
\hline 20 & 1 & 45 & 5 & 2 & 16.538 & 3.1004 \\
\hline
\end{tabular}

TABLe 5: ANOVA fit for yield of crude extracts.

\begin{tabular}{|c|c|c|c|c|c|c|}
\hline Source & Sum of squares & Df & Mean square & F-value & $p$ value & Remark \\
\hline Model & 17.94 & 9 & 1.99 & 1614.91 & $<0.0001$ & Significant \\
\hline A: temperature & 13.17 & 1 & 13.17 & 10669.01 & $<0.0001$ & \\
\hline B: time of extraction & 0.6712 & 1 & 0.6712 & 543.80 & $<0.0001$ & \\
\hline $\mathrm{C}: \mathrm{NaOH}$ concentration & 0.1378 & 1 & 0.1378 & 111.67 & $<0.0001$ & \\
\hline $\mathrm{AB}$ & 0.7110 & 1 & 0.7110 & 576.10 & $<0.0001$ & \\
\hline $\mathrm{AC}$ & 0.0092 & 1 & 0.0092 & 7.44 & 0.0213 & \\
\hline $\mathrm{BC}$ & 1.90 & 1 & 1.90 & 1536.51 & $<0.0001$ & \\
\hline$A^{2}$ & 0.1780 & 1 & 0.1780 & 144.21 & $<0.0001$ & \\
\hline $\mathrm{B}^{2}$ & 0.0257 & 1 & 0.0257 & 20.85 & 0.0010 & \\
\hline $\mathrm{C}^{2}$ & 1.11 & 1 & 1.11 & 901.70 & $<0.0001$ & \\
\hline Residual & 0.0123 & 10 & 0.0012 & & & \\
\hline Lack of fit & 0.0012 & 5 & 0.0002 & 0.1051 & 0.9864 & Not significant \\
\hline Pure error & 0.0112 & 5 & 0.0022 & & & \\
\hline Cor total & 17.95 & 19 & & & & \\
\hline
\end{tabular}

(1) Development of Model Equation. A model equation is a representative equation that mathematically relates the responses to factors. The model of this study would be quadratic for both responses suggested by the Design-Expert software:
Final equation:

$$
\begin{aligned}
\text { yield of crude extracts }= & +16.49+0.9072 * A+0.2048 * B+0.0928 * C+0.2981 * A * B-0.0339 * A * C \\
& -0.4869 * B * C-0.0841 * A^{2}+0.0320 B^{2}-0.2104 C^{2} \\
\text { nicotine content }= & +3.10+0.1167 * A+0.1049 * B+0.0422 * C-1.1058 * A * B-0.0207 * A * C \\
& -0.0349 * B * C+0.0369 * A^{2}-0.0041 * B^{2}-0.0542 * C^{2}
\end{aligned}
$$

where $A$ is coded for temperature $\left({ }^{\circ} \mathrm{C}\right), B$ is extraction time (hr), and $C$ is $\mathrm{NaOH}$ concentration (M).
(2) Model Adequacy Checking. The ANOVA findings for responses that confirm the quadratic model's adequacy yielded a probability $p$ value of less than $5 \%$. The signal-to- 
TABLE 6: ANOVA fit for nicotine content.

\begin{tabular}{|c|c|c|c|c|c|c|}
\hline Source & Sum of squares & Df & Mean square & F-value & $p$ value & Remark \\
\hline Model & 0.6608 & 9 & 0.0734 & 1025.19 & $<0.0001$ & Significant \\
\hline A: temperature & 0.2177 & 1 & 0.2177 & 3040.19 & $<0.0001$ & \\
\hline B: time of extraction & 0.1760 & 1 & 0.1760 & 2457.43 & $<0.0001$ & \\
\hline $\mathrm{C}: \mathrm{NaOH}$ concentration & 0.0285 & 1 & 0.0285 & 397.72 & $<0.0001$ & \\
\hline $\mathrm{AB}$ & 0.0895 & 1 & 0.0895 & 1250.04 & $<0.0001$ & \\
\hline $\mathrm{AC}$ & 0.0034 & 1 & 0.0034 & 47.69 & $<0.0001$ & \\
\hline $\mathrm{BC}$ & 0.0098 & 1 & 0.0098 & 136.15 & $<0.0001$ & \\
\hline $\mathrm{A}^{2}$ & 0.0343 & 1 & 0.0343 & 478.68 & $<0.0001$ & \\
\hline $\mathrm{B}^{2}$ & 0.0004 & 1 & 0.0004 & 6.04 & 0.0338 & \\
\hline $\mathrm{C}^{2}$ & 0.0738 & 1 & 0.0738 & 1030.29 & $<0.0001$ & \\
\hline Residual & 0.0007 & 10 & 0.0001 & & & \\
\hline Lack of fit & 0.0003 & 5 & 0.0001 & 0.8206 & 0.5832 & Not significant \\
\hline Pure error & 0.0004 & 5 & 0.0001 & & & \\
\hline Cor. total & 0.6615 & 19 & & & & \\
\hline
\end{tabular}

noise ratio is calculated with enough accuracy. A four-to-one ratio shows great desirability. The discrepancy between adjusted $R^{2}$ and predicted $R^{2}$ should be less than 0.2 for good statistical agreement. The model is navigating the design space for both responses, as the difference between the adjusted $R^{2}$ and projected $R^{2}$ is 0.0001 and 0.0026 , respectively, and the suitable precessions for responses 1 and 2 are 151.5219 and 138.2832, as shown in Table 7. Figure 4 represents the predicted versus actual response. The measured response data as actual values are in good agreement with the values predicted using the polynomial equations (equations (5) and (6)).

\subsubsection{Effect of Individual Parameters on Yield and Nicotine Contents}

(1) Effect of Temperature. As demonstrated in Figures 5(a) and $5(d)$, temperature has a favorable influence on both yields and nicotine content. The yield of crude extract, as well as the concentration of nicotine, increases as the temperature rises. At low temperatures $\left(30^{\circ} \mathrm{C}\right), 15.5014 \%$ and $3.01835 \%$ crude extract yield and nicotine content are obtained, respectively, whereas, at high temperatures $\left(60^{\circ} \mathrm{C}\right)$, it is $17.3158 \%$ and $3.25166 \%$. Since the boiling points of methanol and ethanol are $65^{\circ} \mathrm{C}$ and $78^{\circ} \mathrm{C}$, respectively, a temperature below $60^{\circ} \mathrm{C}$ is chosen as the upper value of study.

(2) Effect of Extraction Time. Both the yield of crude extract and the nicotine content are linearly related to the time of extraction. Nicotine and other chemicals are extracted from the tobacco filler over time using solvents. The yield enhanced marginally after $5 \mathrm{hrs}$, but the nicotine content increased linearly. The impact of time on yield and nicotine concentration is seen in Figures 5(b) and 5(e).

(3) Effect of $\mathrm{NaOH}$ Concentration. Sodium hydroxide was added to raise the $\mathrm{pH}$ of the solution. The elimination of free nicotine from its salts increased as the $\mathrm{pH}$ increased. The type of nicotine contained in the extract would be free-base nicotine with a $\mathrm{pH}$ over 8 . The yield and nicotine concentration in the extracts are plotted at various molarities, as shown in
Figures 5(c) and 5(f). With increasing molarity of sodium hydroxide up to $2.5 \mathrm{M}$, both yields and nicotine content increased. The yield and nicotine content gradually declined above these molarities. It is observed that, as a result of the development of a complex combination, both yield and nicotine content reach a maximum and then drop.

\subsubsection{Interaction Effects of Parameters on Yield and Nicotine} Contents. Two or more parameters could influence the yield and nicotine contents simultaneously. The effect might be more or less than the effects of individual factors and become significant when the probability level ( $p$ value) should be less than 0.05 .

(1) Interaction Effect of Temperature and Extraction Time. The effects of temperature and extraction time on both responses were substantial. Yield and nicotine content were both poor at low levels of both variables. However, both responses increased as temperature and time increased, as seen in Figure 6(a). The yield, on the contrary, was reaching its maximum at high temperatures and short extraction times. Figure 6(d) indicates that the greatest nicotine concentration was detected when the temperature was high and the time was either at its maximum or minimum. As a result, when the temperature is raised, time has no influence on achieving the maximum of both reactions.

(2) Interaction Effect of Temperature and Sodium Hydroxide Concentration. As temperature and molarity increased, yield and nicotine concentration also increased. $p$ value for both variables was less than 0.05 , indicating that they had a significant influence. Both responses were low when both the variables were at a low level. The yield and nicotine content rose linearly as the temperature climbed to its maximum level at fixed molarity of $\mathrm{NaOH}$. When the temperature was low and the molarity was increased, the responses increased again, but the increment was smaller than when the temperature was constant and the molarity increased, and when both variables were increased, the responses were highest. As a result, raising both temperature and molarity would result in enhanced yield and nicotine content, as illustrated in Figures 6(b) and 6(e). 
TABle 7: Fit summary.

\begin{tabular}{lccccccc}
\hline Response & Std. dev. & Mean & CV (\%) & $R^{2}$ & Adjusted $R^{2}$ & Predicted $R^{2}$ & Adeq. precision \\
\hline 1 & 0.0351 & 16.26 & 0.2158 & 0.9993 & 0.9987 & 0.9986 & 151.5219 \\
2 & 0.0085 & 3.08 & 0.2747 & 0.9989 & 0.9979 & 0.9953 & 138.2832 \\
\hline
\end{tabular}

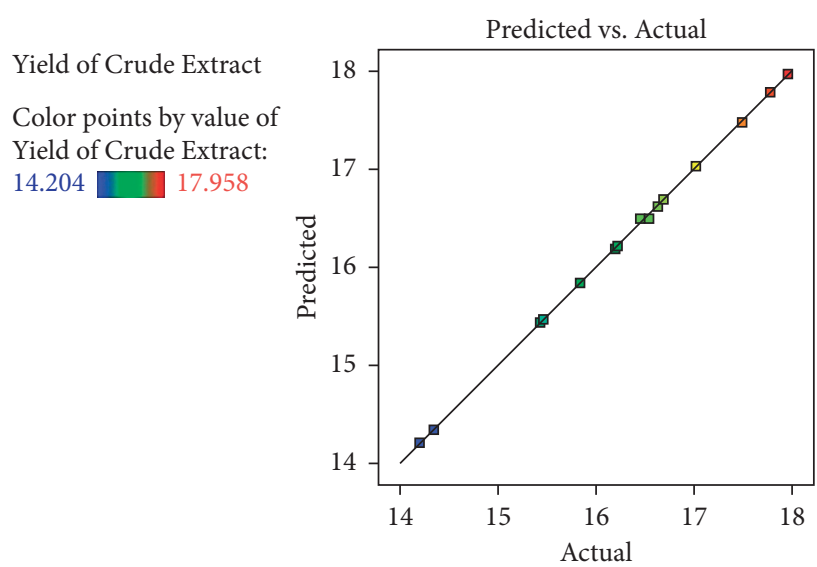

(a)

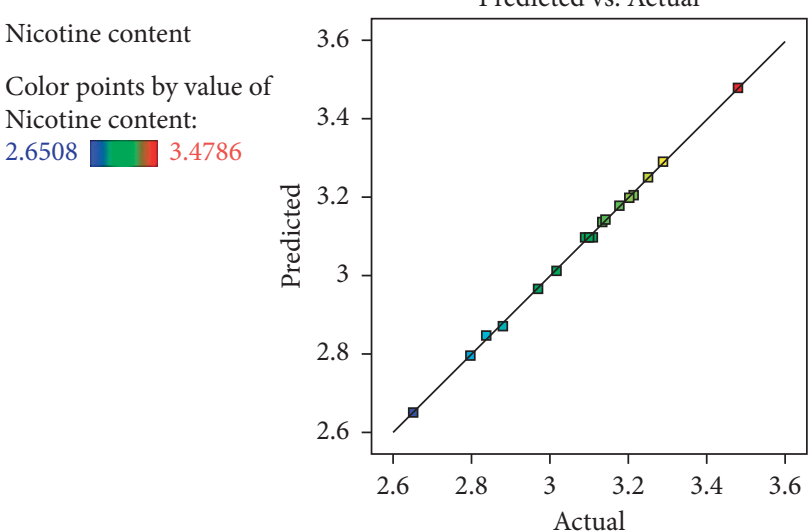

(b)

Figure 4: Actual value versus predicted value for (a) yield of crude extracts and (b) nicotine content.

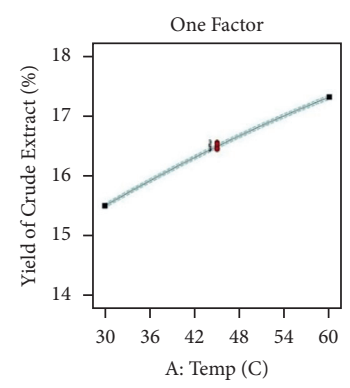

Factor Coding: Actual Yield of Crude Extract (\%)

- Design Points

- - $95 \%$ CI Bands

(a)

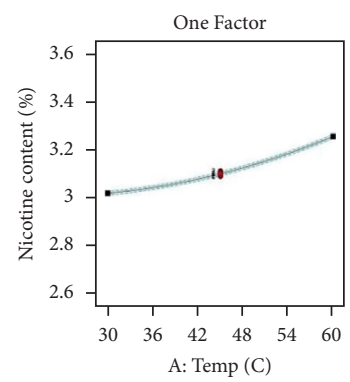

Factor Coding: Actual Nicotine content (\%)

- Design Points _ _ _ 95\% CI Band

(d)

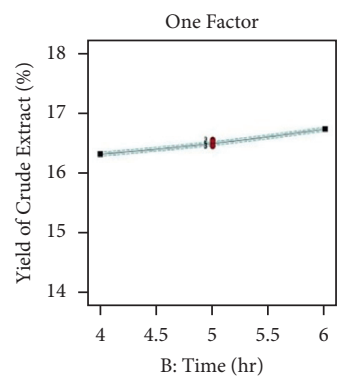

Factor Coding: Actual Yield of Crude Extract (\%)

- Design Points

_ - - 95\% CI Bands

(b)

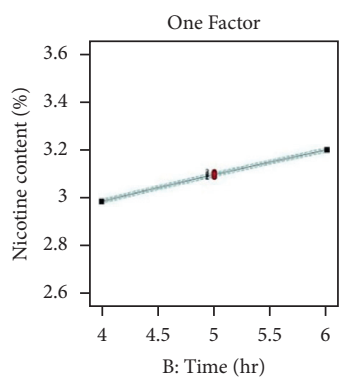

Factor Coding: Actual Nicotine content (\%)

- Design Point

(e)

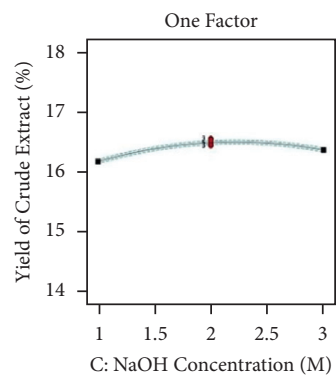

Factor Coding: Actual Yield of Crude Extract (\%)

- Design Points

- - $95 \%$ CI Bands

(c)

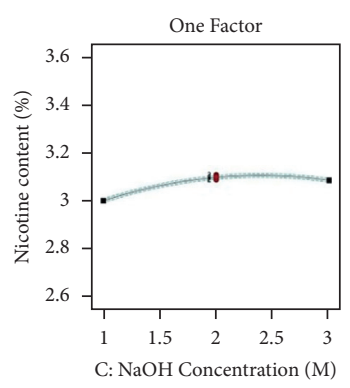

Factor Coding: Actual

Nicotine content (\%)

- Design Points

(f)

Figure 5: (a), (b), (c) Effect of temperature, time of extraction, and $\mathrm{NaOH}$ concentration on yield of extract. (d), (e), (f) Effect of temperature, time of extraction, and $\mathrm{NaOH}$ concentration on nicotine content. 
(3) Interaction Effect of Extraction Time and $\mathrm{NaOH}$ concentration. The interaction effect of time and sodium hydroxide molarity on crude extract yield is shown in Figure 6(c). Because the $p$ value is less than 5\% (i.e., 0.0001), both factors had a substantial impact on it. The yield dropped when both variables climbed to their maximum. The greatest yield is achieved when the extraction period is long and the $\mathrm{NaOH}$ molarity is low. Nicotine content is considerably influenced by the combined effects of time and sodium hydroxide molarity, just as it is by the yield of extract. The impact of time, on the other hand, is larger than that of $\mathrm{NaOH}$ molarity. The high nicotine was observed at high level of time and high level of molarity of sodium hydroxide as depicted in Figure 6(f).

3.2.5. Optimization of Parameters. The goal of optimization is to reduce or increase the number of answers and variables based on the needs. The objective of optimization in this example is to maximize the responses over a variety of variables. The software chooses the variables necessary to accomplish the most desirable goals for this purpose. For both responses, RSM-CCD of Design-Expert 12 found around 78 potential solutions. At optimal circumstances of temperature $60^{\circ} \mathrm{C}$, duration $4 \mathrm{hrs}$, and sodium hydroxide concentration $2.830 \mathrm{M}$, the highest yield of crude extracts and nicotine content were 17.749 and $3.258 \%$, respectively, with maximum desirability of 0.832 or $83.2 \%$ as shown in Figure 7 . The extraction carried out at these optimal conditions presented in Table 8 obtained by RSM-CCD gave the yield of crude extract and nicotine content as 18.24 and $3.35 \%$, respectively, validating the statistical results.

3.2.6. ANN Modeling Using MATLAB. The maximum value of $R^{2}$ and the minimum value of MSE of the testing dataset were used to determine the ideal design of an ANN model. The optimization approach for the training process was the usual backpropagation algorithm. The best adsorption topology was found to be 3-5-2, and the architecture is shown in Figure 8.

The MSE values are $0.00072,0.00744$, and 0.447 , respectively, for training, validation, and testing. $R^{2}$ for the ANN model is 0.9986 , and the model obtained a good connection for the optimum structure from the training data, as shown in Figure 9(a), and it worked rather well in validation and testing, despite some data scattering (Figures 9(b) and 9(c)). As demonstrated in Figure 9(d), the ANN model worked admirably for the dataset. The MSE for the optimized ANN model is plotted versus the epoch number in Figure 10. After 14 epochs, the training process was found to have come to an end. These findings revealed that the experimental data and the anticipated data from the ANN model were in good agreement.

(1) Comparison between RSM and ANN Models. For effective extraction of nicotine from cigarette butts, both the RSM and ANN models were evaluated. Comparative similarity plots were used to do a statistical analysis of the ANN model predicted values of the two target responses. The findings clearly demonstrate that the ANN outperforms the RSM in terms of predictive capacity. The RSM model showed more divergence between anticipated and actual values (residuals) than the ANN model.

\subsection{Physicochemical Characterization of Emulsified} Concentrates. Many physicochemical properties were crucial to estimate the efficiency of concentrated emulsified nicotine insecticides. Some of the basic important properties are described below.

3.3.1. Specific Gravity and Density. Specific gravity can be used for predicting the type of creaming and the degree of spontaneous emulsification of EC. The density calculations were performed with pycnometer balance method using water as a reference at room temperature and pressure. The density measurements were done thrice by varying the volume. The density of concentrated emulsified nicotine was greater than the density of pure nicotine $\left(1.01 \mathrm{~g} / \mathrm{cm}^{3}\right)$ due to the density of emulsifier (Table 9):

$$
\text { specific gravity }(\text { sample })=\frac{\text { mass of sample }}{\text { mass of reference }(\text { distilled water })} \text {. }
$$

For equal volumes of water and sample,

density of sample $=$ specific gravity of sample $\times$ density of water at STP.

3.3.2. Viscosity. The degree of spontaneous emulsification of the emulsified concentrate can be predicted using viscosity. The viscosity measurements were taken with a Vibro viscometer. The Vibro viscometer measures viscosity by vibrating its sensor plates immersed in a sample, and the reading was taken. The viscosity was measured three times at temperatures ranging from 18 to $25^{\circ} \mathrm{C}$. $585.33 \pm 2.52 \mathrm{mPa} \mathrm{s}$ was the calculated mean value.
3.3.3. $\mathrm{pH}$. The $\mathrm{pH}$ is an important parameter because it can reflect the chemical changes in the formulation. Furthermore, changes in $\mathrm{pH}$ over long storage periods can indicate active component degradation or the instability or incompatibility of certain compounds. The extract's $\mathrm{pH}$ was determined by dissolving $5 \mathrm{ml}$ of extract in $10 \mathrm{ml}$ of deionized water and then immersing the $\mathrm{pH}$ meter in the solution and reading the quantity directly at room temperature and $1 \mathrm{~atm}$. The device was calibrated with distilled water at $\mathrm{pH}$ 7.0. The measured average $\mathrm{pH}$ of the concentrated emulsified nicotine was $9.37 \pm 0.03$. 

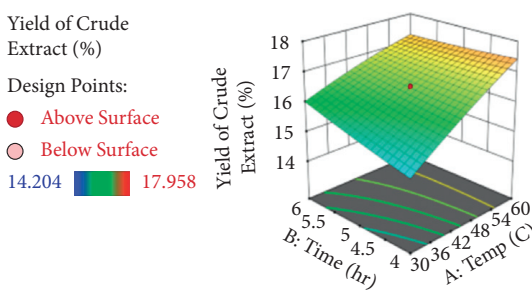

(a)

Nicotine content (\%) Design Points:

- Above Surface

- Below Surface

3.4786

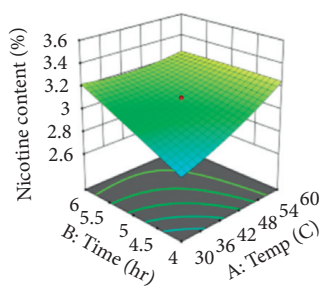

(d)

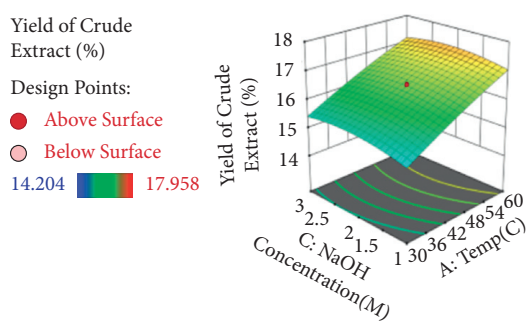

(b)

Nicotine content (\%) Design Points:

- Above Surface

○ Below Surface

2.6508

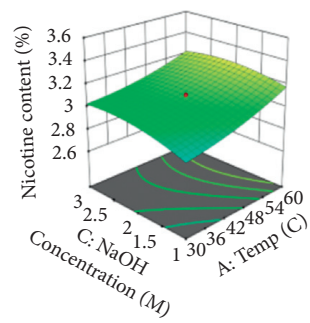

(e)

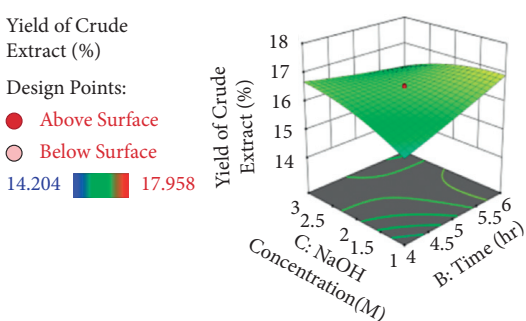

(c)

Nicotine content (\%) Design Points:

- Above Surface

○ Below Surface

$2.6508 \square 3.4786$

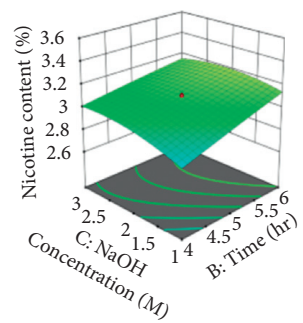

(f)

FiguRE 6: Interactive effects: 3D response surface plots of (a) time, temperature; (b) temperature, $\mathrm{NaOH}$ concentration; (c) time, $\mathrm{NaOH}$ concentration on yield of extract; (d) time, temperature; (e) temperature, $\mathrm{NaOH}$ concentration; (f) time, $\mathrm{NaOH}$ Concentration on nicotine content.
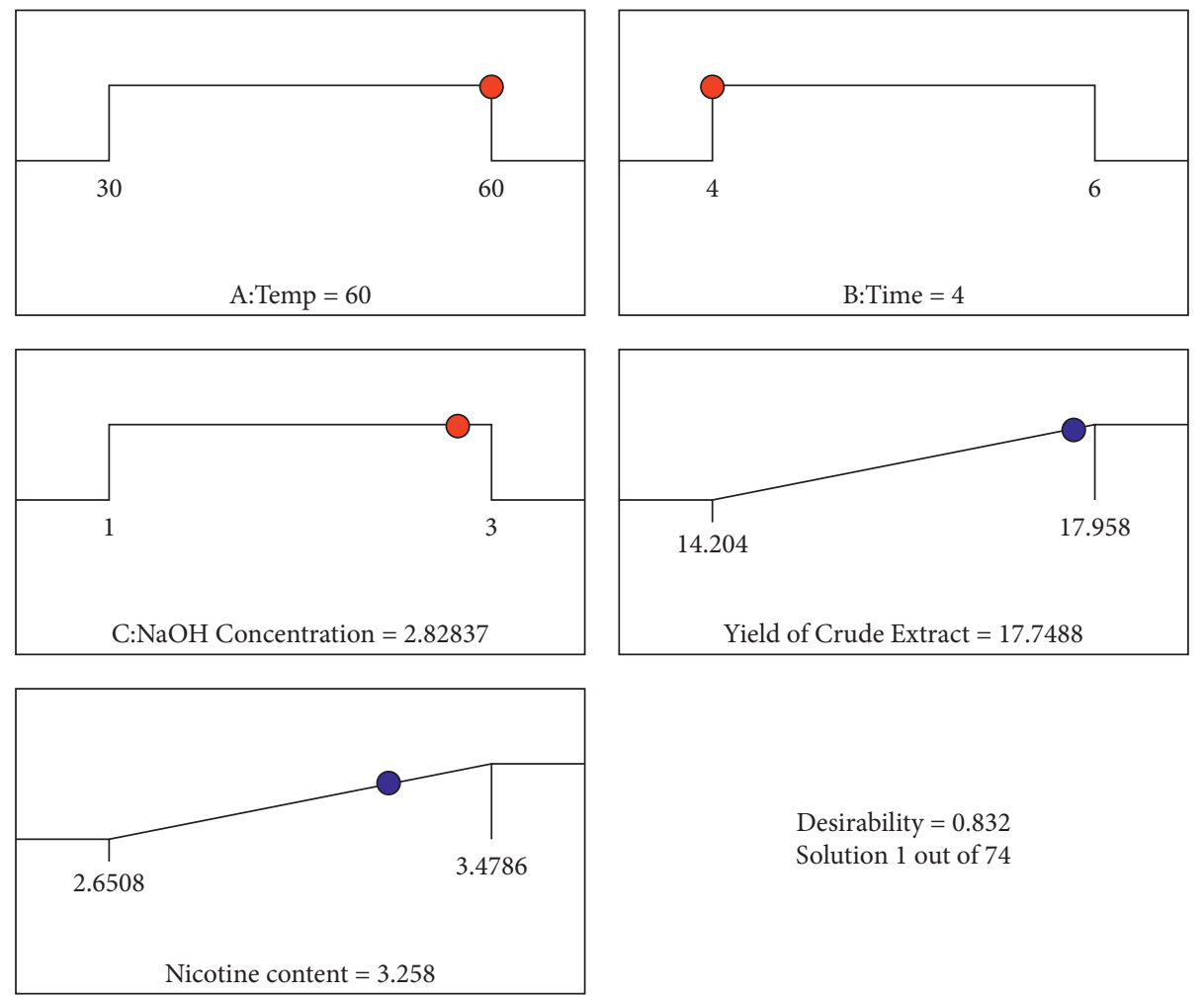

Desirability $=0.832$

Solution 1 out of 74

Figure 7: Ramp plot of optimization condition.

TABLE 8: Constraints of optimization.

\begin{tabular}{|c|c|c|c|c|c|c|}
\hline Name & Goal & Lower limit & Upper limit & Lower weight & Upper weight & Importance \\
\hline A: temperature & Is in range & 30 & 60 & 1 & 1 & 3 \\
\hline B : time of extraction & Is in range & 4 & 6 & 1 & 1 & 3 \\
\hline $\mathrm{C}: \mathrm{NaOH}$ concentration & Is in range & 1 & 3 & 1 & 1 & 3 \\
\hline Yield of crude extracts & Maximize & 14.204 & 17.958 & 1 & 1 & 3 \\
\hline Nicotine content & Maximize & 2.6508 & 3.4786 & 1 & 1 & 3 \\
\hline
\end{tabular}




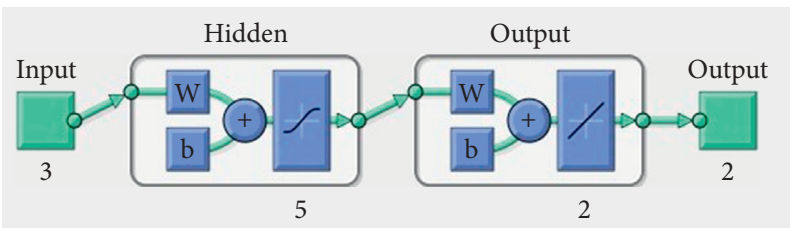

Figure 8: Optimum ANN architecture.
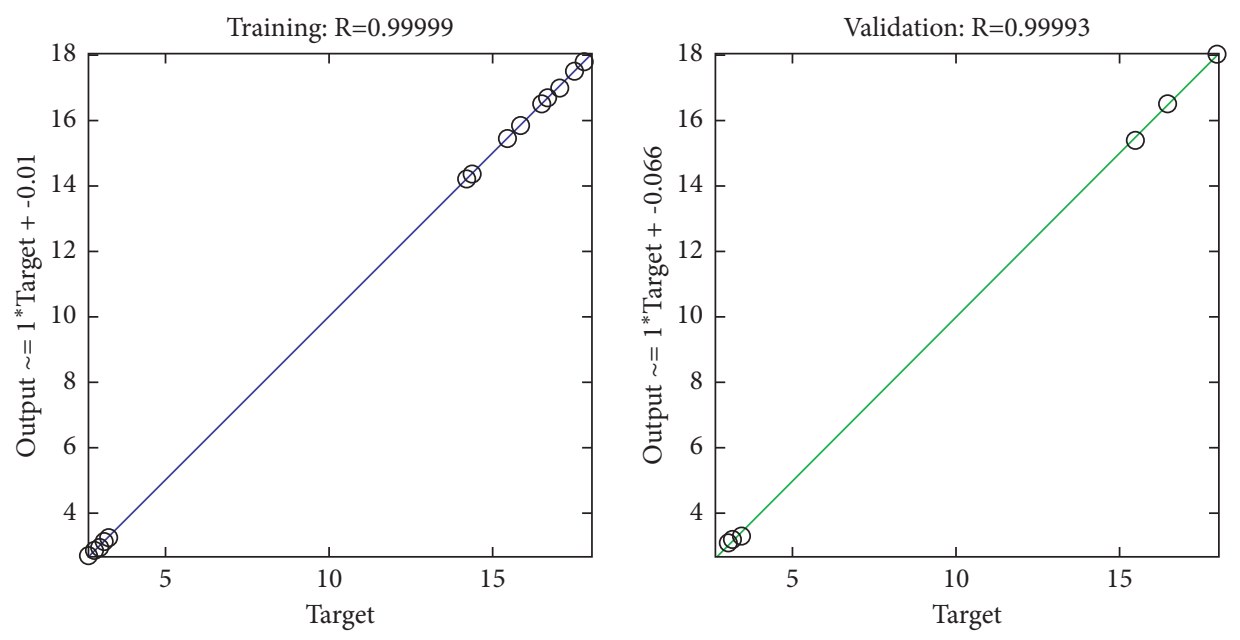

Data

O Data

- Fit

-.... $\mathrm{Y}=\mathrm{T}=\mathrm{T}$

… $\mathrm{Y}=\mathrm{T}$

(a)

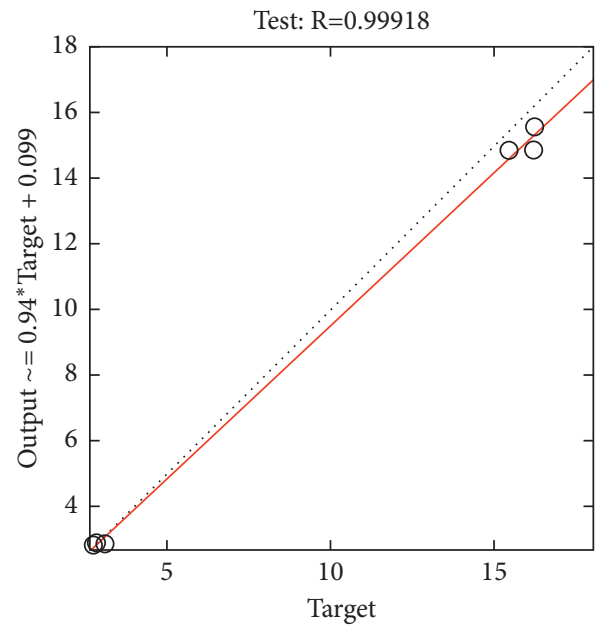

(b)

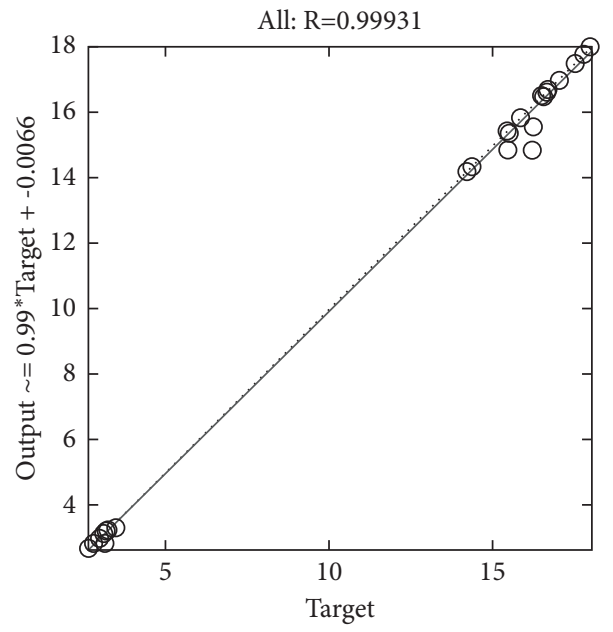
O Data
O Data
- Fit
Fit
… $\mathrm{Y}=\mathrm{T}$

(c)

(d)

FIgURE 9: Output of ANN model: (a) Training, (b) validation, (c) testing, (d) complete data. 


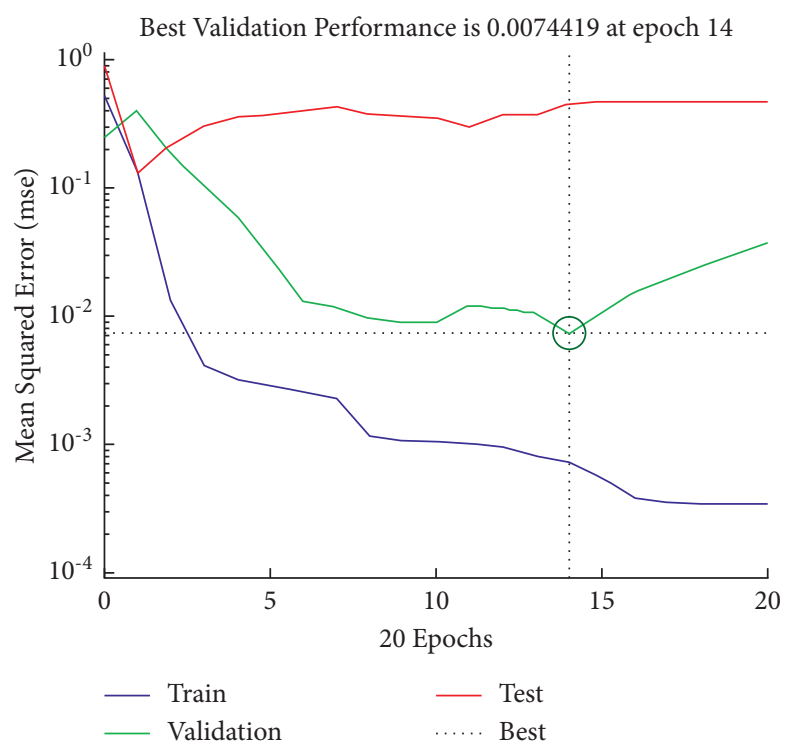

Figure 10: MSE versus the number of epochs in the hidden layer.

TABle 9: Specific gravity and density of EC.

\begin{tabular}{lcccc}
\hline Replication/volume & Mass of sample & Mass of distilled water & Specific gravity & Density $(\mathrm{g} / \mathrm{ml})$ \\
\hline $1 / 10 \mathrm{ml}$ & 12.8091 & 12.4978 & 1.0249 & 1.0218 \\
$2 / 15 \mathrm{ml}$ & 19.0573 & 18.7472 & 1.0165 & 1.0135 \\
$3 / 20 \mathrm{ml}$ & 25.1064 & 24.9987 & 1.0043 & 1.0013 \\
Mean \pm STD & & & $1.0152 \pm 0.0104$ & $1.0122 \pm 0.0103$ \\
\hline
\end{tabular}

TABLE 10: Solubility of EC in tap water.

\begin{tabular}{lcccc}
\hline & Initial mass & Undissolved mass & Mass difference & Solubility (\%) \\
\hline 1 & 5.3500 & 0.0010 & 5.3482 & 99.966 \\
2 & 7.5403 & 0.0026 & 7.5377 & 99.965 \\
3 & 10.0046 & 0.0041 & 10.0005 & 99.959 \\
Mean \pm STD & & & & $\mathbf{9 9 . 9 6 3 \pm 0 . 0 0 4}$ \\
\hline
\end{tabular}

3.3.4. Solubility. Solubility was determined after the mass of the solute dissolved in a specified volume of water and left for an hour. At last, the mass settled at the bottom of the flask was reweighted, and the results are tabulated in Table 10.

3.3.5. Surface Tension. The surface tension is another important parameter to be considered for the formulation of emulsified concentrated products. Surface tension was determined by the interaction of the platinum ring with the surface of the formulations utilized according to the du Nouy ring method, using a Kruss K6 tension meter. The formulated emulsified concentrated nicotine had a surface tension of $34.10 \mathrm{mN} / \mathrm{m}$. The lower surface tension is a desirable property for most agricultural sprays because it facilitates the spreading of droplets upon impact on crops or target surface-active areas and improves penetration and uptake of the products into the plant.

3.3.6. Flash Point. The flashpoint is a criterion for storage and handling that measures a formulation's potential to generate flammable mixtures with air in controlled laboratory settings. By heating a liquid in a container and then placing a small flame just above the liquid surface, flashpoints can be determined experimentally. In the presence of oxygen, a bomb calorimeter records the temperature at which a flash/ignition occurs, called the flashpoint. Product flammability can be divided into three categories: extremely flammable (flashpoint below $0^{\circ} \mathrm{C}$ ), highly flammable (flashpoint below $21^{\circ} \mathrm{C}$ ), and flammable (flashpoint over $21^{\circ} \mathrm{C}$ and below $55^{\circ} \mathrm{C}$ ). The prepared formulation has high flash point values in all storage conditions. The temperature was measured at $87.96 \mathrm{C}$. Hence, formulation was identified to be inflammable.

3.3.7. Stability Study of Emulsified Concentrated Nicotine. The most important factor in emulsion preparation is based on selecting appropriate surfactants that will emulsify the selected ingredients satisfactorily and preserve their stability. The mixture of surfactants plays a major role in surface chemical applications and often exhibits interfacial properties more pronounced than those of the individual surface-active components of the 
TABLE 11: Stability study of EC.

\begin{tabular}{lcccc}
\hline \multirow{2}{*}{ Temperature } & & \multicolumn{2}{c}{ After 18 hrs of initial testing } \\
& Color change & Homogeneity & $p$ H & Density \\
\hline At $4{ }^{\circ} \mathrm{C}$ & No color change & Same & $9.34 \pm 0.01$ & $1.0131 \pm 0.0105$ \\
At room temperature & - & - & - & - \\
At $45^{\circ} \mathrm{C}$ & - & - & - & - \\
\hline
\end{tabular}
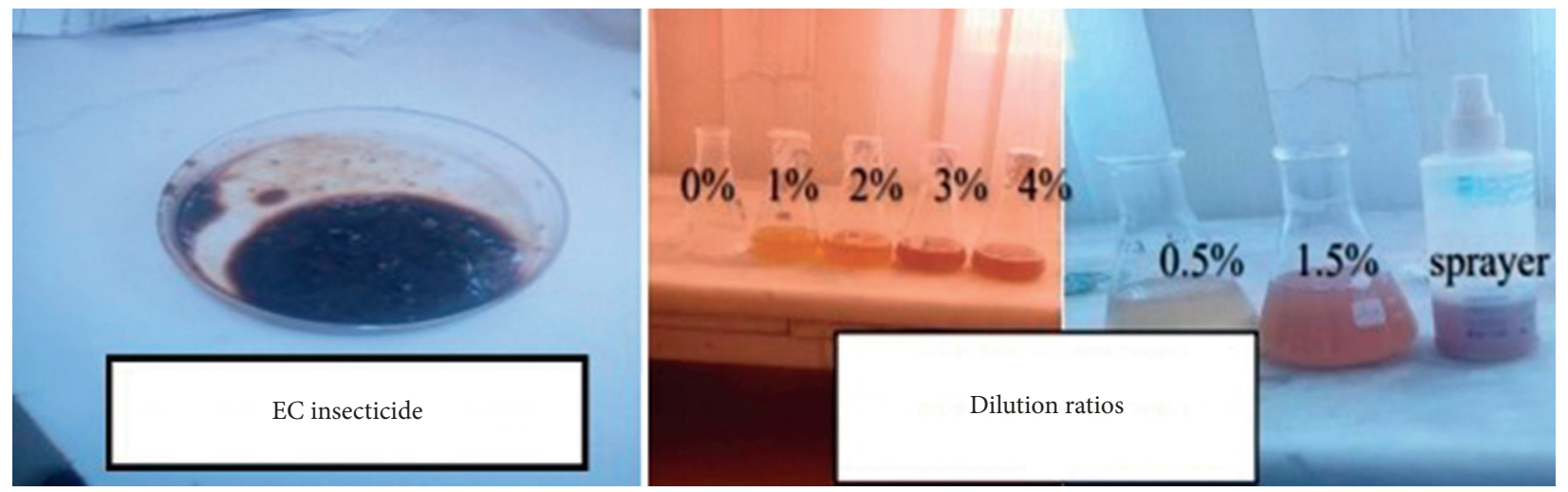

FIgURE 11: Efficiency testing of emulsified concentrates.

TABLE 12: Dilution ratio of EC to solvents.

\begin{tabular}{|c|c|c|c|c|c|}
\hline \multirow{2}{*}{ Dilution ratio (EC: water) } & \multirow{2}{*}{ Total aphids selected } & \multicolumn{2}{|c|}{ Total numbers of aphids died } & \multicolumn{2}{|c|}{$\%$ of aphids died } \\
\hline & & After $8 \mathrm{hrs}$ & After $24 \mathrm{hrs}$ & After $8 \mathrm{hrs}$ & After $24 \mathrm{hrs}$ \\
\hline $0.5: 100$ & 34 & 16 & 31 & 47.058 & 91.177 \\
\hline $1: 100$ & 36 & 23 & 34 & 63.889 & 94.444 \\
\hline $1.5: 100$ & 27 & 21 & 26 & 77.778 & 96.296 \\
\hline $2: 100$ & 29 & 24 & 28 & 82.759 & 96.552 \\
\hline $3: 100$ & 32 & 29 & 32 & 90.625 & 100 \\
\hline $4: 100$ & 27 & 25 & 27 & 92.593 & 100 \\
\hline $0: 100$ (pure water) & 22 & 1 & 3 & 4.546 & 13.636 \\
\hline
\end{tabular}

mixtures. Stability studies were conducted by varying the temperature and time. For these factors, the $\mathrm{pH}$, density, color change, and homogeneity were reevaluated as shown in Table 11. The temperature change occurred under the incubator.

Hence, the product was stable if it was stored at any place for months. According to [26], the formulated emulsified concentrated nicotine was stable for six months without any physicochemical property changes.

\subsection{Efficiency Testing of Emulsified Concentrate. Different} masses of the active ingredients of EC were dissolved in $100 \mathrm{ml}$ of tap water to evaluate the efficiency of the dilution ratios used for field application (Figure 11). The experimental species (cabbage aphids) were collected from the market. Table 12 presents the study results carried out at different EC dilution ratios for different time periods of $8 \mathrm{hrs}$ and $24 \mathrm{hrs}$. The selection of dilution ratio depended on the time interval at which the insecticides kill all insect pests, the season of application, place (area) of application, types of crops, and nature of insect pests [28]. If the amount of active ingredients is high, the time taken to kill all pests will be low. However, it affects the crops and other useful vertebrate species and pollinators found around there. During the summer, the rain can wash the insecticide from crops before it fully contacts with insects. Therefore, the active ingredient present in the solvent should be higher than that of spring, winter, or autumn season. In this study, the dilution ratio of $0.5: 100$ has low efficacy. Dilution ratios of $1.5: 100,2: 100$, $3: 100$, and $4: 100$ have shown greater efficacy in $24 \mathrm{hrs}$. However, the concentration of nicotine used as an insecticide was $0.5-1 \% \mathrm{w} / \mathrm{w}$ for vegetables [26]. Effective insecticides have to control or kill the pests for two or three days. An insecticide that kills all pests in a day is very toxic and may cause a problem in a food chain. Hence, $1 \mathrm{~g}$ of EC with $100 \mathrm{~g}$ of water dilution ratio is considered the most efficient dilution ratio.

\section{Conclusions}

Bioinsecticides have several advantages over conventional pesticides as they act specific to the target insects and are less harmful to nontarget species/environment. The conversion 
of cigarette waste to insecticides addresses two issues: the mitigation of environmental impacts resulting from the large volumes of cigarette waste generated and replacing chemical insecticides with bioinsecticides. The present study has used seven different brands of cigarettes that were smoked mostly in Ethiopia. The key findings of the study are as follows:

The extraction uses the solvent mixture containing ethanol and methanol. The optimal combination is obtained as $3: 1$.

The RSM-CCD studies predicted the maximum yield of the crude extract and nicotine content $17.749 \%$ and $3.258 \%$, respectively, at a temperature of $60^{\circ} \mathrm{C}$, time of $4 \mathrm{hrs}$, and molarity of sodium hydroxide of $2.83 \mathrm{M}$.

The ANN performed better than RSM-CCD in terms of predictive and estimation ability.

The emulsified concentrated nicotine insecticide has a physicochemical property of inflammable, viscous, basic, stable, wettable, and highly soluble in water.

The produced insecticide was effective in controlling cabbage insect pests.

\section{Data Availability}

All the data are provided in the manuscript.

\section{Conflicts of Interest}

The authors declare that they have no conflicts of interest.

\section{References}

[1] M. Banožić, J. Babić, and S. Jokić, "Recent advances in extraction of bioactive compounds from tobacco industrial waste-a review," Industrial Crops and Products, vol. 144, Article ID 112009, 2020.

[2] E. Slaughter, R. M. Gersberg, K. Watanabe, J. Rudolph, C. Stransky, and T. E. Novotny, "Toxicity of cigarette butts, and their chemical components, to marine and freshwater fish," Tobacco Control, vol. 20, no. 1, pp. i25-i29, 2011.

[3] J. Torkashvand, M. Farzadkia, H. R. Sobhi, and A. Esrafili, "Littered cigarette butt as a well-known hazardous waste: a comprehensive systematic review," Journal of Hazardous Materials, vol. 383, Article ID 121242, 2020.

[4] Y. Yang, J. Cheng, V. M. Garamus, N. Li, and A. Zou, "Preparation of an environmentally friendly formulation of the insecticide nicotine hydrochloride through encapsulation in chitosan/tripolyphosphate nanoparticles," Journal of Agricultural and Food Chemistry, vol. 66, no. 5, pp. 1067-1074, 2018.

[5] Z. Tassew and B. S. Chandravanshi, "Levels of nicotine in Ethiopian tobacco leaves," SpringerPlus, vol. 41 page, 2015.

[6] H. Guliani, S. Gamtessa, and M. Çule, "Factors affecting tobacco smoking in Ethiopia: evidence from the demographic and health surveys," BMC Public Health, vol. 19, no. 1, pp. 1-17, 2019.

[7] Y. Deressa Guracho, G. S. Addis, S. M. Tafere et al., "Prevalence and factors associated with current cigarette smoking among Ethiopian university students: a systematic review and meta-analysis," Journal of Addiction, vol. 2020, Article ID 9483164, 10 pages, 2020.

[8] D. Erku and E. Tesfaye, "Tobacco control and prevention efforts in Ethiopia pre- and post-ratification of WHO FCTC: current challenges and future directions," Tobacco Induced Diseases, vol. 17, pp. 1-10, 2019.

[9] T. E. Novotny, "Environmental accountability for tobacco product waste," Tobacco Control, vol. 29, no. 2, pp. e055023-139, 2020.

[10] S. Vahidhabanu, "Study of cigarette butts extract as corrosiveinhibiting agent in J55 steel material," International Journal of Research in Engineering and Technology, vol. 03, no. 1, pp. 444-452, 2014.

[11] A. Mohajerani, A. A. Kadir, and L. Larobina, "A practical proposal for solving the world's cigarette butt problem: recycling in fired clay bricks," Waste Management, vol. 52, pp. 228-244, 2016.

[12] A. Mohajerani, S. Qun Hui, C. Shen et al., "Implementation of recycling cigarette butts in lightweight bricks and a proposal for ending the littering of cigarette butts in our cities," $M a$ terials, vol. 13, no. 18, pp. 4023-18, 2020.

[13] A. M. Hossain and S. M. Salehuddin, "Analytical determination of nicotine in tobacco leaves by gas chromatographymass spectrometry," Arabian Journal of Chemistry, vol. 6, no. 3, pp. 275-278, 2013.

[14] H. Dieng, S. Rajasaygar, A. H. Ahmad et al., "Turning cigarette butt waste into an alternative control tool against an insecticide-resistant mosquito vector," Acta Tropica, vol. 128, no. 3 , pp. 584-590, 2013.

[15] F. A. Pratiwi, T. S. Utami, and R. Arbianti, "Using ultrasonic assisted extraction to produce a bioinsecticide from cigarette butt waste and green solvent to control armyworm infestation," International Journal of Technology, vol. 11, no. 7, pp. 1329-1336, 2020.

[16] H. Yu, H. Tang, and P. Xu, "Green strategy from waste to value-added-chemical production: efficient biosynthesis of 6hydroxy-3-succinoyl-pyridine by an engineered biocatalyst," Scientific Reports, vol. 4, no. 1, pp. 1-8, 2014.

[17] T. E. Novotny and E. Slaughter, "Tobacco product waste: an environmental approach to reduce tobacco consumption," Current Environmental Health Reports, vol. 1, no. 3, pp. 208-216, 2014.

[18] S. Firdausiah, H. Firdaus, T. Hidayat, and M. Alfliadhi, "The Comparison of three different methods on extraction of cigarette butt as natural insecticide," Inorganica Chimica Acta, vol. 13, no. 2, pp. 55-59, 2020.

[19] M. V. Ratnam, C. Karthikeyan, K. N. Rao, and V. Meena, "Magnesium oxide nanoparticles for effective photocatalytic degradation of methyl red dye in aqueous solutions: optimization studies using response surface methodology," Materials Today: Proceedings, vol. 26, pp. 2308-2313, 2020.

[20] V. R. Myneni, N. R. Kanidarapu, and M. Vangalapati, "Methylene blue adsorption by magnesium oxide nanoparticles immobilized with chitosan (CS-MgONP): response surface methodology, isotherm, kinetics and thermodynamic studies," Iranian Journal of Chemistry and Chemical Engineering, vol. 39, no. 6, pp. 29-42, 2020.

[21] A. Ciric, B. Krajnc, D. Heath, and N. Ogrinc, "Response surface methodology and artificial neural network approach for the optimization of ultrasound-assisted extraction of polyphenols from garlic," Food and Chemical Toxicology, vol. 135, Article ID 110976, 2020.

[22] R. Qadir, F. Anwar, M. A. Gilani, S. Zahoor, M. Misbah ur Rehman, and M. Mustaqeem, "RSM/ANN based optimized 
recovery of phenolics from mulberry leaves by enzymeassisted extraction," Czech Journal of Food Sciences, vol. 37, pp. 99-105, 2019.

[23] K. Ameer, S.-W. Bae, Y. Jo, H.-G. Lee, A. Ameer, and J.-H. Kwon, "Optimization of microwave-assisted extraction of total extract, stevioside and rebaudioside-A from Stevia rebaudiana (Bertoni) leaves, using response surface methodology (RSM) and artificial neural network (ANN) modelling," Food Chemistry, vol. 229, pp. 198-207, 2017.

[24] J. Zhang, G. Lin, X. Yin, J. Zeng, S. Wen, and Y. Lan, “Application of artificial neural network (ANN) and response surface methodology (RSM) for modeling and optimization of the contact angle of rice leaf surfaces," Acta Physiologiae Plantarum, vol. 42, no. 4, 2020.

[25] H. Katepalli, "Formation and stability of emulsions: effect of surfactant- particle interactions and particle shape," Open Access Dissertations, vol. 295, pp. 1-70, 2014.

[26] J. Puripattanavong, C. Songkram, L. Lomlim, and T. Amnuaikit, "Development of concentrated emulsion containing nicotiana tabacum extract for use as pesticide," Journal of Applied Pharmaceutical Science, vol. 3, no. 11, pp. 16-21, 2013.

[27] T. Pagano, M. R. Bida, and R. J. Robinson, "Laboratory activity for the determination of nicotine in electronic cigarette liquids using gas chromatography-mass spectrometry," Journal of Laboratory Chemical Education, vol. 3, no. 3, pp. 37-43, 2015.

[28] K. Yimenu, "Effect of TobaccoConcentration (Tobaccumrestica) to Protect Cabbage Aphid (Brevicornyebrassicae) on Cabbage crop (brassica oleracea)," Indian Journal of Entomology, June, vol. 6, pp. 299-304, 2018. 